ARTIGO

CO https://doi.org/10.22481/praxisedu.v15i34.5506

\title{
A INTERDISCIPLINARIDADE INTRÍNSECA NAS AÇÕES DESENVOLVIDAS NO PIBID
}

\author{
THE INTRINSIC INTERDISCIPLINARITY INSIDE THE ACTIONS DEVELOPED IN \\ PIBID
}

\author{
LA INTERDISCIPLINARIEDAD INTRÍNSECA EN LAS ACCIONES \\ DESARROLLADAS EN EL PIBID
}

Ana Márcia Fernandes Tucci de Carvalho Universidade Estadual de Londrina - Brasil

Andreia Maria Cavaminami Lugle Universidade Estadual de Londrina - Brasil

Sandra Regina Ferreira de Oliveira Universidade Estadual de Londrina - Brasil

\begin{abstract}
Resumo: Esta pesquisa ${ }^{1}$ analisa questões relativas à efetivação de abordagens interdisciplinares nos diferentes subprojetos em desenvolvimento no PIBID/UEL. Para tanto, aprofundamos o estudo da temática em formação de professores e no conceito de interdisciplinaridade. Teoricamente, abordamos como a interdisciplinaridade é apresentada nos documentos oficiais sobre o PIBID, logo a escolha metodológica foi a análise documental. Empiricamente, coletamos dados junto aos relatos dos participantes de um evento e afunilamos no estudo de um projeto desenvolvido na área de Matemática, com o tema Cultura Africana. A análise dos dados aponta que a interdisciplinaridade presente no PIBID/UEL concretiza-se a partir de projetos e/ou temas sob a regência do professor de áreas específicas. Colocamo-nos frente ao desafio da necessidade de compreender tais ações como transdisciplinares e expandi-las.
\end{abstract}

Palavras chave: Formação de Professores. Interdisciplinaridade. PIBID.

\begin{abstract}
This research analyzes issues related to the implementation of interdisciplinary approaches in the different subprojects under development in PIBID/UEL. For this purpose, we deepen in teacher training and the concept of interdisciplinarity. Theoretically, we approach how the interdisciplinarity is presented in the official documents which rule PIBID, so the methodological choice was the documentary analysis. Empirically, we collected data from the reports of the participants during an

\footnotetext{
1 A pesquisa que deu origem ao texto foi submetida ao Comitê de Ética e aprovada. Número CAAE
} 67724517.2.0000.5231
\end{abstract}


event and we focused on the study of a project developed in the area of Mathematics, with the African Culture theme. The data analysis points out that the interdisciplinarity included in PIBID / UEL materializes from projects and/or subjects under the regency of the teacher of specific areas. We are faced with the challenge of understanding such transdisciplinary actions and expanding them to other subprojects.

Key words: Teacher Training. Interdisciplinary. PIBID.

Resumen: Esta investigación analiza cuestiones relativas a la efectividad de enfoques interdisciplinarios en los diferentes subproyectos en desarrollo en el PIBID / UEL. Por lo tanto, profundizamos el estudio de la temática en formación de profesores y en el concepto de interdisciplinariedad. Teóricamente, abordamos cómo la interdisciplinaridad es presentada en los documentos oficiales sobre el PIBID, luego la elección metodológica sea el análisis documental. Empíricamente, reconectamos datos junto a los relatos de los participantes de un evento y profundizamos en el estudio de un proyecto desarrollado en el área de matemáticas, con el tema Cultura Africana. El análisis de los datos apunta que la interdisciplinaridad presente en el PIBID / UEL se concreta a partir de proyectos y / o temas bajo la dirección del profesor de áreas específicas. Nos situamos frente al desafío de la necesidad de comprender tales acciones multiciplinares y expandirlas.

Palabras-clave: Formación de profesores. Interdisciplinariedad. PIBID.

\section{Introdução}

No ano de 2007, após alterações realizadas na Coordenadoria de Aperfeiçoamento de Pessoal de Nível Superior (CAPES) e no Ministério da Educação (MEC) tendo em vistas a implementação do preconizado no Plano de Desenvolvimento da Educação (PDE), as políticas públicas voltadas à formação de professores, anteriormente a cargo somente do MEC, passaram a ser de responsabilidade de ambas as instituições. A partir de então, a CAPES coloca em ação programas com formatos inovadores tratando de formação para o magistério, viabilizando bolsas e recursos para custeio em diversos projetos, dentre os quais nos deteremos neste estudo no Programa Institucional de Bolsas de Iniciação à Docência (PIBID) que envolve formadores de professores, docentes das instituições de Ensino Superior, professores da Educação Básica e graduandos dos cursos de licenciaturas.

Partindo do pressuposto de que o PIBID, desde sua execução, possibilitou novos desenhos quanto à formação docente, tanto inicial quanto continuada, e também fomentou nas universidades discussões e ações com o objetivo de avançar no sentido de compreender as diferentes dimensões que compõem a prática pedagógica na escola, elegemos neste artigo investigar e expor algumas ações desenvolvidas no PIBID da Universidade Estadual de 
Londrina, com especial atenção para a efetivação de propostas interdisciplinares no contexto escolar. As análises aqui apresentadas compõem, parcialmente, um projeto de pesquisa em desenvolvimento na Universidade Estadual de Londrina.

Em 2010, ano de implantação do PIBID na UEL, participavam apenas seis licenciaturas (Física, Matemática, Química, Ciências Biológicas, Letras Estrangeiras - Inglês e Filosofia) abrangendo um total de 122 bolsistas de iniciação à docência (IDs)- alunos das licenciaturas, 14 supervisores - professores da Educação Básica e quatro escolas, com projetos tão somente destinados ao Ensino Médio.

O recorte temporal selecionado para balizar o estudo disposto neste artigo abarca o ano de 2014, período no qual todas as 15 licenciaturas da UEL estavam envolvidas no programa, além de um subprojeto denominado Interdisciplinar, totalizando assim 16 subprojetos em desenvolvimento. Em 2014, conforme dados constantes na página da UEL, participavam do programa 788 bolsistas de iniciação à docência, 121 supervisores, 41 professores - coordenadores, atendendo 49 escolas da cidade de (nome da cidade) e região ${ }^{2}$.

Em dezembro de 2017, o programa completou uma década a considerar como marco a Portaria Normativa $\mathrm{n}^{\circ} 38$ de 12/12/2007 (BRASIL, 2007). Durante esse período, os anos de 2010 e 2014 foram marcados pelo crescimento qualitativo e quantitativo do programa que revelou ser eficaz em suas ações atingindo a Educação Básica e o Ensino Superior. O resultado de uma avaliação externa do PIBID solicitada em 2013 pela CAPES destacou:

Constata-se que o PIBID vem possibilitando, na visão de todos os envolvidos com sua realização, um aperfeiçoamento da formação inicial de docentes para a educação básica. Em particular destacamos a apreciação dos licenciandos que participam deste Programa os quais declaram reiteradamente em seus depoimentos como o PIBID está contribuindo fortemente para sua formação profissional em função de propiciar contato direto com a realidade escolar nos inícios de seu curso, contato com a sala de aula e os alunos, possibilitando-lhes conhecer de perto a escola pública e os desafios da profissão docente. (GATTI; ANDRÉ, 2013 apud BRASIL, 2013a, p. 08).

No final de 2015, em meio a um contexto de crise política e econômica, não se efetivou a substituição dos bolsistas IDs que concluíram os respectivos cursos de graduação, o que levou à redução significativa no número de alunos bolsistas em todo país. Esta situação de precarização do programa é, certamente, merecedora de profunda reflexão, considerando a

2 Como consta em http://www.capes.gov.br/educacao-basica/capespibid/documentos-pibid Acesso em $19 / 02 / 2017$. 
importância que o PIBID vem desempenhando no processo de formação de professores, porém, tal tema está além do recorte proposto neste artigo.

O ponto focal deste texto é analisar questões relativas à efetivação de abordagens interdisciplinares nos diferentes subprojetos em desenvolvimento no PIBID/UEL a partir do apresentado nos Grupos de Trabalho (GT) no IV Encontro Institucional do PIBID/UEL, realizado em novembro de 2014. O Encontro Institucional do PIBID/UEL é realizado anualmente e tem por objetivo promover um momento de reflexão sobre as atividades desenvolvidas no âmbito dos subprojetos do PIBID das licenciaturas. $\mathrm{O}$ formato do evento até o ano de 2013 consistia em agregar todos os participantes em torno das apresentações das ações desenvolvidas nas escolas expostas em forma de painel. Com a ampliação do programa tal formato tornou-se improdutivo quanto a conseguir efetivar trocas entre os participantes, pois cada qual precisava se dividir entre fazer sua apresentação e conhecer o que os outros realizaram. Registra-se também que a devolutiva ao final do encontro, possibilitava conhecer os impactos do PIBID na formação do discente, nas escolas e nas universidades ${ }^{3}$ porém, de forma fragmentada.

No ano de 2014, a equipe gestora ${ }^{4}$ propôs mudanças estruturais no IV Encontro Institucional, reunindo em Grupos de Trabalho (GTs) diferentes escolas e áreas de subprojetos, valorizando a apresentação realizada pelos supervisores e/ou bolsistas IDs das atividades desenvolvidas nas escolas e incentivando a troca de experiências entre os mesmos. A hipótese neste momento, levantada pela equipe, era a de que, ao reunirmos sujeitos das diversas disciplinas, diferentes perspectivas metodológicas e epistemológicas estariam forçosamente reunidas para o diálogo, o que resultaria em uma análise menos fragmentada dos impactos do PIBID quanto à formação do discente e à atuação nas escolas. Os resultados comprovaram a hipótese aventada e os relatórios dos GTs propiciaram considerável avanço quanto à análise do programa no interior da universidade, assim como quanto ao planejamento das metas para o ano seguinte.

Durante o ano de 2014, a equipe gestora, reunida com os coordenadores das áreas do conhecimento, fez notar que o tema da interdisciplinaridade carecia de ser tratado de maneira mais atenciosa. A importância de deter o olhar para a questão das práticas interdisciplinares, independente das contribuições da mesma no processo ensino aprendizagem, estava

\footnotetext{
${ }^{3}$ O documento que rege o PIBID, a Portaria 96, de 18 de julho de 2013(BRASIL, 2013b), estabelece as diretrizes para a avaliação anual do Programa nas instituições participantes.

4 A equipe gestora do PIBID UEL era formada por um coordenador institucional e três coordenadoras pedagógicas
} 
diretamente relacionada com o preconizado na Portaria $096^{5}$, de 18 de julho de 2013, que aponta como um dos objetivos do PIBID:

Art. 4 - IV - inserir os licenciandos no cotidiano de escolas da rede pública de educação, proporcionando-lhes oportunidades de criação e participação em experiências metodológicas, tecnológicas e práticas docentes de caráter inovador e interdisciplinar que busquem a superação de problemas identificados no processo de ensino aprendizagem. (BRASIL, 2013 b, p. 02, grifo nosso).

Para atingir tal objetivo é preconizado, no Artigo 6 da referida Portaria, que o projeto proposto pela instituição aborde as:

[...] diferentes características e dimensões da iniciação à docência, entre as quais: $\S$ II - desenvolvimento de ações que valorizem o trabalho coletivo, interdisciplinar e com intencionalidade pedagógica clara para o processo de ensino-aprendizagem. (BRASIL, 2013b, p.03, grifo nosso).

Até então, as ações da gestão frente ao desafio de alavancar as práticas interdisciplinares nos subprojetos em desenvolvimento, pautavam-se em um conceito de interdisciplinaridade muito mais voltado a aproximação de diferentes docentes, e em decorrência de diferentes áreas, em torno de uma temática específica. Considerando toda a estrutura da escola quanto à organização do tempo e do espaço e as limitações advindas da formação recebida nos cursos de licenciatura que operam com uma lógica disciplinar quanto às disciplinas a serem ensinadas na escola, raras ações interdisciplinares, com esse formato, se efetivavam no programa.

Ao final do IV Encontro Institucional, deparamo-nos com outras formas de abordagens interdisciplinares que, necessariamente, não eram destacadas e valorizadas por seus protagonistas como tais, por exemplo, a interdisciplinaridade que ocorria a partir de um único professor que ao selecionar um tema como conteúdo a ser trabalhado, estabelecia diálogos com outras áreas do conhecimento.

Este artigo apresenta os estudos que realizamos a partir desta constatação, uma vez que a interdisciplinaridade ocorreu no trabalho desenvolvido por um único docente. Para tanto, aprofundamos o estudo da temática em formação de professores e o conceito de

\footnotetext{
${ }^{5}$ Este documento pode ser baixado de http://www.capes.gov.br/educacao-basica/capespibid/documentos-pibid Acesso em 19/02/2017.
} 
interdisciplinaridade e apresentamos a análise advinda dos dados coletados junto a relatórios dos GTs do IV Encontro do PIBID/UEL ${ }^{6}$ e, por fim, tecemos as considerações finais.

\section{Formação de Professores}

Saviani (2011) argumenta que durante este último século, entre 1933 e 1998, a matrícula dos alunos brasileiros aumentou vinte vezes, considerados os níveis de Ensinos Fundamental, Médio e Superior, representando "praticamente a universalização do acesso ao Ensino Fundamental" (SAVIANI, 2011, p. 8). Acompanhando a quantidade, todavia, está a insuficiente qualidade da formação dos professores e os diversos problemas das instituições formadoras.

Considerados os dois modelos principais existentes na história de formação de professores, quais sejam, um que advoga a cultura geral e o domínio do conteúdo específico como suficiente, acreditando que a formação didático-pedagógica advirá deste conhecimento específico, e o segundo, pautado na crença de que a formação completa do professor deve, necessariamente, contemplar ações que interfiram em seu efetivo preparo didático pedagógico, Saviani (2011) retrata que foi o primeiro modelo que predominou nas universidades, instituições formadoras dos futuros professores dos Ensinos Fundamental e Médio.

Este é apenas um, dentre diversos motivos, pelos quais o PIBID deve ser considerado um programa da mais suma importância entre os desenvolvidos pelas instituições, uma vez que traz em sua própria essência a possibilidade de pareceria com o professor que já atua nas escolas, exercendo influência direta na preparação didático-pedagógica do aluno em formação.

Saviani (2011) propõe enfrentamentos aos diversos dilemas que caracterizam a política de formação docente como: (i) considerar uma formação 'orgânica' da formação docente, centrada na excelência do conhecimento oriundo da universidade, lócus privilegiado para a formação; (ii) considerar uma política educacional que fuja ao imediatismo, pautada na percepção da necessidade de programas de longa duração; (iii) abolir ao máximo a burocratização facilitando o acesso aos centros de formação, primando pelo estímulo intelectual; (iv) a articulação entre a teoria e a prática, conteúdo e forma, para dinamizar o

\footnotetext{
${ }^{6}$ Ao final do IV Encontro Institucional, cada coordenador de GT entregou um relatório síntese das apresentações e das principais temáticas abordadas pelo grupo, acompanhado dos slides das apresentações. Este material está arquivado na UEL.
} 
movimento do trabalho pedagógico, e, finalmente, (v) a necessidade de articulação entre as instituições formativas e as escolas, considerado seu funcionamento, tomando o modo de funcionamento das escolas como ponto de partida para a organização do processo formativo (SAVIANI, 2011).

Desta maneira, reconhecemos que não é possível atender à demanda de formação de professores em seus múltiplos aspectos, sem considerar as demandas do exercício do trabalho docente, sem considerar a realidade das escolas, suas efetivas condições de execução da tarefa de educar, sem considerar a relação do sujeito com os saberes, quer sejam de natureza teórica, quer sejam de natureza prática.

As relações com os saberes são fundamentais para a formação docente. Charlot apresenta uma formulação simples, "a relação com o saber é uma forma da relação com o mundo" (CHARLOT, 2000, p. 77). Para este autor, quando discutimos a relação com o saber em última instância estamos sempre falando do sujeito, visto que se trata sempre de relação de um sujeito com o mundo que o cerca, mediatizado pelos espaços que o circundam, com a cultura na qual está inserido; trata-se do sujeito imerso num universo que o constitui, e é a partir deste referencial que ele pode agir em busca de saber, de conhecimento.

O espaço de formação institucional e de formação escolar, como extensão, são ambos capazes de aprimorar o conhecimento dos sujeitos envolvidos, articulando a necessidade da complementação entre as diferentes habilidades necessárias para o tornar-se professor. É neste sentido que o documento "Relatório de Gestão PIBID, 2009 - 2013" (BRASIL, 2013a) tendo por referência autores como Schon, Nunes e Pimenta, destaca:

[...] como eixo orientador da formação a interação profícua de diferentes saberes sobre a docência: conhecimentos prévios e representações sociais manifestados principalmente pelos alunos das licenciaturas -, o contexto, vivências e conhecimentos teórico-práticos dos professores em exercício na educação básica; e, por fim, os saberes da pesquisa e da experiência acadêmica dos formadores de professores, lotados nas instituições de ensino superior. Essa interação enriquece o processo formativo da docência com a finalidade de aperfeiçoar os elementos teórico-práticos para o magistério e possibilitar que o trabalho dos futuros professores seja mobilizado pela açãoreflexão-ação. (BRASIL, 2013a, p.69).

Interação pode ser apontada como uma das características mais marcantes do PIBID. No programa, trabalham lado a lado alunos em formação para a docência, professores no exercício da docência efetiva na educação básica e os professores das universidades, formadores de professores e pesquisadores. O que se constata, pela nossa experiência, é que o 
PIBID redefiniu os espaços e as relações entre os diferentes níveis da escolaridade no país, pois, por exemplo, supervisores adentraram nos eventos científicos das academias expondo os resultados de seus trabalhos e/ou tornaram-se coformadores de novos professores ao trabalhar com os bolsistas IDs nas escolas; coordenadores adentraram nas escolas redimensionando o seu olhar para esse espaço e, consequentemente, o que ensinavam sobre o mesmo. Enfim, romperam-se alguns paradigmas que sustentavam uma lógica muito específica sobre quem, quando e como se forma um professor e, com isso, outros desafios foram se interpondo para a ampliação e manutenção de tal política pública no país.

Em outro documento intitulado "Um estudo avaliativo do Programa Institucional de Bolsa de Iniciação à Docência (Pibid)", publicado no ano de 2014 (GATTI et.al., 2014), também apontam para a importância das interações entre diferentes realidades no processo de formação para a docência e indicam a necessidade de repensar os atuais modelos de formação:

[...] a partir do diálogo com a realidade e as situações concretas do trabalho docente, bem como a urgência de superar a relutância de muitas instituições formadoras em reconhecer que esta nova epistemologia da formação de professores precisa ser incorporada ao discurso e às práticas formativas no ensino superior, adotando uma relação mais próxima e respeitosa com as escolas e comunidades docentes. (GATTI; ANDRÉ, 2013 apud BRASIL, 2013a,p.100).

Assumindo os pressupostos apontados pelos autores nesta breve abordagem quanto ao tema formação de professores inferimos que ampliar a compreensão sobre o que são e como se efetivam as práticas interdisciplinares no programa PIBID e, em decorrência nas escolas, é um caminho para estudar essas interações.

\section{$O$ conceito de interdisciplinaridade}

Como exposto, um dos objetivos do PIBID é formar professores que desenvolvam "práticas docentes de caráter inovador e interdisciplinar" nas escolas. Sabemos que são vários os conceitos para a palavra "interdisciplinaridade" na literatura pedagógica. Com o objetivo de verificar qual o conceito assumido no Programa realizamos uma pesquisa buscando como o termo interdisciplinaridade aparece nos documentos oficiais que instituem, regulamentam e avaliam o PIBID. A base documental desta fase da pesquisa ficou assim definida: Portaria $\mathrm{n}^{\circ}$ 260/2010 (BRASIL, 2010) e Portaria n96/2013 (BRASIL, 2013b) - documentos que 
instituem e normatizam o programa; Relatório de Gestão - PIBID 2009 - 2013 (BRASIL, 2013a) e o Relatório "Um estudo avaliativo do Programa Institucional de Bolsa de Iniciação à Docência - PIBID” (GATTI et.al., 2014), documentos que avaliam as ações do programa

A análise comparativa entre a Portaria $n^{\circ} 260 / 2010$ e a Portaria $n^{\circ}$ 96/2013 possibilita acompanhar quais as normativas estabelecidas quanto efetivação de uma abordagem interdisciplinar no Programa. Na Portaria $n^{\circ}$ 260/2010, com doze páginas, o termo interdisciplinaridade é tomado duas vezes, na apresentação dos objetivos e ao normatizar as funções do Coordenador Institucional, descritos a seguir:

[...] inserir os licenciandos no cotidiano de escolas da rede pública de educação, proporcionando-lhes oportunidades de criação e participação em experiências metodológicas, tecnológicas e práticas docentes de caráter inovador e interdisciplinar que busquem a superação de problemas identificados no processo de ensino-aprendizagem [...] articular docentes de diferentes áreas, visando ao desenvolvimento de atividades integradas na escola conveniada e a promoção da formação interdisciplinar. (BRASIL, 2010, p.09).

Na Portaria $n^{\circ}$ 96/2013, total de vinte quatro páginas, o termo é tomado cinco vezes: em dois objetivos do programa, citados neste texto; sobre os subprojetos interdisciplinares das Instituições de Ensino Superior (IES); sobre a função do coordenador institucional e sobre a função do coordenador de área. Esta portaria aponta para a possibilidade das IES desenvolverem subprojetos interdisciplinares com o objetivo de envolver as áreas do conhecimento em ações comuns "com ações que valorizem a intersetorialidade e a conexão dos conhecimentos presentes da educação básica" (BRASIL, 2013b, p. 16). Neste sentido, as funções do coordenador do institucional e de área ressaltam para a elaboração e desenvolvimento de subprojetos interdisciplinares.

Verifica-se que no processo de aperfeiçoamento do PIBID, no que pode ser acompanhado pelo exposto nos dois documentos em análise, a interdisciplinaridade é progressivamente valorizada, inclusive com a abertura para o desenvolvimento de subprojetos interdisciplinares para além dos subprojetos das licenciaturas específicas. Na universidade Estadual de Londrina, no ano de 2014, o subprojeto interdisciplinar foi proposto envolvendo as áreas de Geografia, Química, Música, Artes e Pedagogia.

No Documento “Relatório de Gestão - PIBID 2009 - 2013 (BRASIL, 2013a), com 129 páginas, o termo interdisciplinaridade é encontrado doze vezes. O documento em tela apresenta um resumo dos programas implementados pela Diretoria de Formação de 
Professores da Educação Básica - DEB, órgão pertencente à CAPES. É notório que a interdisciplinaridade é assumida como um critério basilar nos projetos o que confere coerência quanto às políticas públicas em desenvolvimento sob a responsabilidade da DEB. O princípio interdisciplinar está presente na criação e desenvolvimento, por exemplo, do programa de apoio aos Laboratórios Interdisciplinares de Formação para Professores (LIFE). No que se relaciona especificamente a abordagem da interdisciplinaridade no PIBID, encontramos a reprodução do objetivo já citado na análise anterior e a informação de que o projeto interdisciplinar é uma das áreas do PIBID com maior número de bolsas, atrás somente das áreas de Pedagogia, Matemática e Biologia (BRASIL, 2013a, p. 51). As demais tratativas encontradas no que concerne ao tema em estudo são elaboradas tendo por base o próximo documento sobre o qual expomos os resultados da análise a seguir.

O documento "Um estudo avaliativo do Programa Institucional de Bolsa de Iniciação à Docência - PIBID” foi publicado pela Fundação Carlos Chagas no ano de 2014 e apresenta os resultados de um estudo realizado no ano de 2013:

Em 2013, a Capes propôs uma avaliação externa do PIBID, mesmo o programa sendo considerado ainda novo. Por meio de projeto firmado entre o MEC e a Unesco, foram convidadas duas reconhecidas especialistas em formação de docentes: a Prof ${ }^{a}$. Dr ${ }^{a}$. Bernadete A. Gatti e a $\operatorname{Prof}^{a}$. Dr ${ }^{a}$. Marli E. D. A. André. Coube a elas definir uma metodologia de trabalho que alcançasse o surpreendente número de cerca de 38.000 participantes (à época, o Pibid estava com 45.000 bolsistas) que responderam a múltiplas questões sobre o programa, refletindo sobre seus fundamentos, seu desenvolvimento, sua gestão, suas perspectivas e seus impactos e desdobramentos no cotidiano da formação, seja nas instituições formadoras, seja nas escolas públicas onde acontece a prática dos bolsistas de iniciação. (GATTI et.al., 2014, p.6).

Destaca-se que o resultado deste estudo foi uma das bases a partir da qual o Relatório de Gestão - PIBID, 2009 - 2013 (BRASIL, 2013a) foi elaborado. Trata-se de um documento detalhado sobre o PIBID. Segundo exposto no mesmo, a coleta dos dados foi realizada pela Coordenação Geral de Programas de Valorização do Magistério (CGV) da Capes e deu-se por meio de questionários aplicados via sistema Google-Drive envolvendo "licenciados bolsistas", terminologia utilizada para se referir aos Bolsistas IDs, supervisores, coordenadores de áreas e coordenadores institucionais.

Neste documento, o termo interdisciplinaridade é encontrado dezenove vezes somando trechos das respostas dos participantes da pesquisa citados integralmente no texto, como também nas análises realizadas pelas autoras. Nas respostas de todas as categorias 
envolvidas na pesquisa, encontramos referência à interdisciplinaridade. Identificamos a cautela das autoras em tratar o termo nas análises acompanhado da expressão "e/ou trabalho coletivo", pois é fato que o mesmo é citado nas respostas tanto para indicar questões relacionadas à composição do conhecimento como para indicar ações que reúnem pessoas, ações em grupo. Não obstante a essa questão, conclui-se que o PIBID é um programa com ações que estimulam e favorecem o trabalho coletivo e/ou interdisciplinar (GATTI et.al., 2014) fator que promove de forma mais potente a formação de professores.

O estudo nos documentos demonstra que a prática interdisciplinar é apontada como um princípio importante para a formação de professores tanto que o mesmo está contemplado em vários programas em desenvolvimento pela DEB e é assumida no PIBID como um de seus objetivos. No entanto, tais documentos não possibilitam compreender qual o conceito de interdisciplinaridade que é assumido em tais programas. Já destacamos que a definição do termo é bastante plural. Avançamos então, em uma pesquisa bibliográfica para compreender mais a respeito das compreensões sobre o que vem a ser interdisciplinaridade.

Para o dicionário Houaiss (2004, p. 1633), a palavra 'interdisciplinar' significa "1.que estabelece relações entre duas ou mais disciplinas ou ramos de conhecimento; 2.que é comum a duas ou mais disciplinas”. Houaiss e Villar apresentam 'multidisciplinar' como "que contém, envolve, distribui-se por várias disciplinas e pesquisas", sinônimo de pluridisciplinar (HOUAISS; VILLAR, 2004, p.1977). Já 'transdisciplinar' não está dicionarizada, mas o prefixo 'trans' significa "além de, para lá de; depois de", fornecendo as acepções de "1. Situação ou ação além de; 2. Travessia, transposição; 3. Transferência, cessão; 4. Mudança, transformação" (HOUAISS; VILLAR, 2004, p. 2749). Considerar esta ideia de interdisciplinaridade implica em fazer a junção de duas ou mais áreas de conhecimento, ou partes delas, para vislumbrar um dado fenômeno, analisar um certo objeto de estudo; e a transdisciplinaridade seria um passo adiante, uma possibilidade de considerar para além das disciplinas.

Nicolescu (2010) utiliza o termo 'multidisciplinar' para esta ideia de referência ao estudo de um objeto simultaneamente por várias disciplinas, exemplificando com a utilização de um quadro, o qual pode ser estudado não apenas na disciplina de História da Arte, mas também, no contexto de História Geral, de forma a enriquecer o estudo do objeto em si, apresentando diferentes perspectivas para o mesmo tema.

Segundo esta autora, o conceito de 'interdisciplinaridade' tem um objetivo diferente da multidisciplinaridade, visto que num contexto interdisciplinar "trata-se de transferir 
métodos de uma disciplina para outra" (NICOLESCU, 2010, p.12), podendo ser realizada em três graus (ou maneiras diferentes). Num primeiro caso, pode ser um 'grau de aplicação', ocorre quando métodos de uma certa disciplina são transferidos para outra, por exemplo, quando métodos da física nuclear são utilizados na medicina; um segundo tipo é o 'grau epistemológico', por exemplo, quando métodos da lógica formal são transferidos para um área geral como o direito e; finalmente, o terceiro grau é o 'grau de geração de novas disciplinas', quando por exemplo, métodos da Matemática são utilizados para criar uma área de estudos como física nuclear ou transferidos para análises na bolsa de valores.

A autora reserva o termo 'transdisciplinaridade' para o estudo que ultrapassa as disciplinas, "a transdisciplinaridade diz respeito àquilo que está ao mesmo tempo entre as disciplinas, através das diferentes disciplinas e além de todas as disciplinas" (NICOLESCU, 2010, p.13). A autora relaciona os diferentes conceitos: "Disciplinaridade, multidisciplinaridade, inter-dicisplinaridade e transdisciplinaridade são como quatro flechas no disparo de um único arco: o conhecimento". (NICOLESCU, 2010, p.13).

$\mathrm{O}$ que podemos concluir ao inquirir sobre os sufixos agregados a palavra “disciplinaridade", a saber - multi, inter, trans - é que cada um deles reveste-se de características específicas quanto a construção do conhecimento e, em decorrência, remete a formatos diferentes quanto ao processo de formação de professores. Roggero (2010, p.139) aponta que a universidade é o lócus natural para que a interdisciplinaridade ocorra, uma vez que é o lugar onde "se constrói, se organiza e se distribui conhecimento", todavia, não raramente, a estrutura da formação dos graduandos não incentiva, ou mesmo não permite, esta possibilidade de articulação entre as disciplinas, fazendo com que os currículos sejam fragmentados e mesmo dentro de um único curso, as disciplinas sejam consideradas partes de um todo, ao invés de um único conjunto de conhecimento.

Por ora, na esteira do postulado por Roggero (2010) quanto às limitações relacionadas a uma efetiva articulação das disciplinas, avançamos no sentido de buscar compreender o que torna tão difícil essas aproximações. Lélé \& Norgaard (2005) apontam quatro principais barreiras para trabalharmos com projetos envolvendo interdisciplinaridade.

Primeiro, há a barreiras de valores, crenças dos pesquisadores e professores, os quais estão embutidos em todos os tipos de questão e estágios, momentos em que as posições teóricas, estilos de pesquisas e opiniões dos sujeitos envolvidos nos projetos, das diferentes instâncias são colocadas à prova e percebidas conflituosas por causa das concepções prévias e preconceitos dos sujeitos. Desta maneira, para estes autores, 
[...] o julgamento coletivo requerido nas pesquisas que envolvem interdisciplinaridade é especialmente difícil. Torna-se preocupante com a possibilidade dos cientistas realizarem uma 'conversa entre surdos', porque as disciplinas alegam neutralidade ética e apresentam 'olhos fechados' para suas próprias posições normativas. (LÉLÉ; NORGAARD, 2005, p. 968, tradução nossa).

O segundo ponto importante, é que as pesquisas que são realizadas de modo interdisciplinar podem estudar o mesmo fenômeno, mas de diferentes pontos de vista, dentro dos próprios modos de conceber o fenômeno característico de cada área envolvida. Para os autores, isto é problemático, pois manter a fidelidade a um certo tipo de pensamento característico pode parecer mais importante do que analisar a complexidade do fenômeno como um todo e induz a perder a possibilidade de explicar as particularidades de um certo contexto. De modo geral, pensar que há vários 'lados de um determinado fenômeno' deve ser uma ideia abandonada, para ser possível abarcar a complexidade de um fenômeno como um todo.

A terceira barreira destacada por Lélé e Norgaard (2005), mais enfatizada na literatura sobre interdisciplinaridade, refere-se às diferenças de concepções epistemológicas e nos respectivos métodos de estudo, análise para pesquisas e outras noções primordiais referentes a cada campo envolvido para estabelecimento das 'verdades' que a pesquisa pode produzir. No contexto interdisciplinar, há relativização destes pontos de vistas, o que produz conflitos entre os pesquisadores.

Finalmente, os autores apontam como uma quarta barreira para trabalharmos como projetos que valorizam a interdisciplinaridade o fato que de a própria sociedade como um todo, da qual as universidades e centros de pesquisa fazem parte, valoriza certas áreas do conhecimento mais do que outras, causando diferenças na importância considerada na validade de alguns métodos e abordagens em detrimento de outros.

Os autores ainda consideram que o "primeiro tipo de barreira (diferenças de valores) nem é diretamente, nem tampouco facilmente discernível do segundo tipo (diferenças entre teorias, modelos ou visões do mundo)" (LÉLÉ; NORGAARD, 2005, p. 968, tradução nossa). O mesmo pode ser afirmado sobre as outras duas barreiras, que também se mesclam.

Fato posto é que se aliarmos as conclusões advindas do relatório elaborado por Gatti et.al (2014), o disposto nos documentos oficiais do PIBID e os estudos conceituais aqui apresentados entendemos que é evidente a necessidade de avançar sobre outras lógicas quanto à forma de se construir conhecimento e que as características do mundo contemporâneo 
exigem cada vez mais lógicas "multi, inter ou trans" disciplinares. Tal pressuposto se aplica também quanto à formação de professores e nos remete a indagar quais as transformações necessárias nos cursos de formação de docente para que possamos caminhar nessa direção. Para avançar com a discussão, contribuímos apresentando os resultados de um estudo que teve por objetivo compreender e analisar quais as ações interdisciplinares, ou correlatas, desenvolvidas no PIBID - UEL. O diferencial do estudo aqui apresentado é que o mesmo foi construído com a lógica de pesquisa invertida, ou seja, a partir de um fato específico ocorrido no ano de 2015, voltamos o olhar para o ano de 2014 para rever o que não vimos, mas que lá já se apresentava, ainda que com outros formatos.

\section{A interdisciplinaridade nas ações do PIBID - UEL}

A equipe de gestão do PIBID - UEL, com o intuito de planejar, organizar e auxiliar nas ações do programa na instituição, trabalha com reuniões mensais com os coordenadores de área, analisando vários documentos que são produzidos pelos subprojetos, tais como: portfólios produzidos anualmente pelos Bolsistas IDs; sínteses dos grupos de trabalhos (GTs) elaborados pelos coordenadores do GT ao final dos encontros anuais que envolvem coordenadores de área, supervisores e Bolsistas IDs; e relatórios anuais de autoria dos coordenadores de área, que retratam todas as ações do programa na área sob sua coordenação. As informações constantes em tais documentos possibilitam traçar estratégias de ações tendo em vistas cumprir com os objetivos do mesmo. Em 2014, uma das metas estabelecidas foi alavancar o desenvolvimento de ações interdisciplinares e foi solicitada especial atenção dos coordenadores de área quanto a esse aspecto. O tema foi abordado, apresentado e debatido junto aos coordenadores, como estava estabelecido na Portaria nº 096/2013 (Brasil, 2013b).

Como trabalhado neste texto, não há uma definição nos documentos do PIBID quanto ao conceito de interdisciplinaridade como também não há explicitações de como implementar uma prática interdisciplinar. De certa forma, ao acompanhar o desenvolvimento dos subprojetos nas escolas, por meio dos documentos já citados e pelo relato dos coordenadores, não havia identificação de diferentes áreas trabalhando com um mesmo tema e/ou não havia identificação de trabalhos coletivos entre as diferentes áreas que desenvolviam PIBID em uma mesma escola e tal situação era frustrante porque conduzia ao entendimento que não se concretizava a tão almejada prática interdisciplinar. Todo mês na reunião dos 
coordenadores de área, de uma forma ou outra, era cobrada a realização de projetos interdisciplinares na escola.

Foi nesse contexto que nos deparamos com a situação que passamos a relatar: no $\mathrm{V}$ Encontro Institucional do PIBID, realizado em novembro de 2015, a coordenadora de área do subprojeto de História PIBID/UEL era a coordenadora de um Grupo de Trabalho no qual se apresentou uma equipe do subprojeto PIBID de Matemática. As razões que levaram à composição dos GTs com esse formato propiciando que diferentes áreas se misturassem foram tratadas neste texto. Esta coordenadora de História, ao entregar o relato do GT para a equipe de gestão, verbalizou: "há mais interdisciplinaridade no PIBID do que imaginamos". Nosso questionamento, a partir da fala desta coordenadora foi justamente no sentido de visualizar esta interdisciplinaridade que não víamos e entender em quais contextos ocorrem. Para tanto, voltamos à análise de todos os relatos de GTs, incluindo os dos encontros institucionais anteriores. Nossa constatação foi a de que mesmo antes de 2015 ocorriam ações que poderiam ser entendidas como interdisciplinares. Relataremos aqui o que ocorreu em 2014, durante as apresentações do IV Encontro Institucional do PIBID.

Foram analisados vinte e três relatos produzidos no IV Encontro Institucional do PIBID, em 2014. Importante retomar que os GTs agregam coordenadores de área, supervisores e bolsistas ID. Ao conhecer o teor dos documentos é perceptível a integração entre as equipes e valorização do PIBID por parte de todos. Os relatos, em sua maioria, apresentam a mesma estrutura: sínteses do que foi apresentado por cada grupo, cada qual de uma área de conhecimento, e análises quanto ao impacto do PIBID na formação dos bolsistas IDs, nos supervisores, nos coordenadores de área, na escola e na comunidade e impactos nos alunos das escolas envolvidas. Um dos objetivos é facilitar a elaboração do relatório anual que é enviado à CAPES.

No que tange ao tema deste estudo, na maioria dos relatos encontramos referências que se aproximam de uma abordagem interdisciplinar, ainda que a terminologia não seja explicitamente apresentada nos documentos, pois as propostas dos projetos nas áreas abarcavam temas contemporâneos e que requeriam um tratamento interdisciplinar devido a sua complexidade. Encontramos projetos e/ou propostas com os seguintes temas: Meio Ambiente; Feminismo; Homofobia; Cyberbullying; Cultura Mexicana; Minha cidade durante a Ditadura Militar; Copa do mundo: benefícios e malefícios do mega evento no Brasil; Terras indígenas; Alimentos transgênicos; A legitimidade da representação dos partidos políticos no 
Brasil e vários recorte para o estudo da cidade considerando seus problemas econômicos e ambientais, a cultura e a história.

Para aprofundar a análise sobre a interdisciplinaridade presente em tais projetos e/ou propostas selecionamos um deles e ampliamos a pesquisa para além do constante. Optamos por aquele que suscitou na coordenadora de área a constatação de que "há mais interdisciplinaridade no Pibid do que imaginamos" em 2015, o subprojeto de Matemática. Prosseguimos o estudo convidando a professora supervisora de Matemática para que nos fornecesse a apresentação efetuada no IV Encontro Institucional e nos explicasse como os bolsistas ID e ela realizaram a atividade em sala de aula. Às considerações da supervisora agregamos reflexões quanto ao espectro teórico a partir do qual as ações desenvolvidas podem ser compreendidas.

\section{Subprojeto de Matemática: Cultura Africana e Matemática}

Especificamente no tange ao conhecimento da disciplina de Matemática, há muitos avanços oriundos da área de Educação Matemática, consolidada no país, mas o número de desafios também é significativo. A disciplina de Matemática é, ainda, considerada 'difícil' e os índices de reprovação nesta disciplina são altos em todos os anos escolares, como qualquer professor da Educação Básica pode atestar.

Silveira (2011) argumenta que a expressão 'Matemática é difícil' é uma construção resultante de diversas leituras humanas sobre a disciplina de Matemática, o que cria um discurso instituído. A autora defende que marcas desta afirmação podem sem encontradas ao longo da história da humanidade, em muitos discursos veiculados pela mídia, nas falas dos professores de Matemática, fatores estes que geram ressonâncias no sentido do que é difícil para os próprios alunos. Segundo a autora, torna-se importante valorizar práticas educativas e situações de ensino/aprendizagem em que os alunos atuem como produtores de sentido, que consigam eles próprios redefinir os significados pré-estabelecidos sobre a Matemática, valorizando suas potencialidades.

Uma possível resposta a esta necessidade de ressignificação pode ser encontrada nas práticas transdisciplinares, já que permitem mesclar conhecimentos de áreas diferentes, podendo despertar o interesse dos estudantes para a realização das tarefas. Gerdes (2012) analisa potencialidades do uso de ideias Matemáticas oriundas da cultura africana na educação Matemática. $\mathrm{O}$ autor exemplifica tal uso por meio de atividades que valorizam as 
"artes e artesanato - a cestaria, a cerâmica, o desenho entre outras -, a pesca, os jogos e puzzles, a comunicação, a representação gráfica até à numeração e à contagem" (GERDES, 2012, p. 149).

A introdução do contexto das práticas e cultura africana nas aulas de Matemática foi explorada por uma das supervisoras do subprojeto de Matemática, no ano de 2013, sendo apresentada no GT no IV Encontro do PIBID da UEL, em 2014. Naquele ano, os trabalhos do PIBID Matemática propostos pela equipe da supervisora abarcaram duas atividades que tiveram como "pano de fundo" a cultura africana. A primeira, desenvolvida junto a alunos do Ensino Médio, incluía o estudo da história da capoeira, a aprendizagem de alguns passos de capoeira e o jogo do Jongo, com a posterior realização de atividades de geometria voltadas para este tema, como lateralidade, noção espacial, conceitos relacionados às figuras geométricas de círculo e circunferência.

Outra atividade desenvolvida pela equipe da professora, junto a alunos do ensino fundamental de Matemática referiu-se ao jogo Mancala, um jogo de estratégia, o qual permitiu o desenvolvimento de raciocínio lógico matemático, a percepção da necessidade de desenvolvimento de estratégias para a resolução, além de exigir a aprendizagem de aritmética e combinatória para fazer estimativas das probabilidades de captura de peças, de acordo com as disponíveis em cada jogada.

Seguindo algumas concepções propostas por GERDES (2012), o desenvolvimento destas atividades sempre seguiram determinadas etapas: a primeira era uma discussão aberta junto aos estudantes das escolas públicas sobre suas vivências e conhecimentos relacionados ao tema, explorando as hipóteses que apresentavam, explorando as concepções prévias dos estudantes; a segunda etapa consistia em formar pequenos grupos e aprofundar, a partir dos conhecimentos preliminares discutidos, a temática inicial; na terceira etapa, os alunos socializavam as discussões dos pequenos grupos, valorizando os diferentes pontos de vistas, aprendendo a lidar com a diversidade das opiniões; a quarta etapa privilegiou a sistematização do conteúdo já adquirido, procurando estabelecer uma articulação entre o tema proposto e o conteúdo específico que poderia ser trabalhado. Neste exemplo, a disciplina específica foi a Matemática, abrangendo conteúdos de geometria, raciocínio lógico, desenvolvimento de estratégias para resolução de problemas, entre outros. A quinta e última etapa consistiu no desenvolvimento de atividades de caráter avaliativo, valorizando as aprendizagens individuais e grupais, num processo de construção de conhecimento que não envolveu apenas a área específica de Matemática, mas também apresentou correlações com outros campos do 
conhecimento como História do Brasil (tema da escravidão), com História Geral (cultura africana), Geografia (localização de países, características geográficas, etc); Sociologia (aspectos relacionados à exploração do trabalho negro, valorização da mulher negra), Artes (padrões geométricos das culturas africanas), Língua Portuguesa (escrita e interpretação de texto).

O detalhamento teórico e metodológico tecido a partir do subprojeto apresentado possibilita-nos compreender como, no próprio campo da Matemática, a abordagem interdisciplinar/transdisciplinar se estrutura, pautada nas contribuições da área de Educação Matemática. Formulamos a hipótese de que esse fato se estende às outras disciplinas e o estudo desses aspectos sobre as alterações no campo, aqui em específico na Matemática, quando este assume as especificidades do campo da Educação, trariam contribuições importantes para entender os novos desenhos quanto aos saberes escolares.

\section{Conclusões}

A partir de uma afirmação casual "há mais interdisciplinaridade do que imaginamos", feita por uma coordenadora de um dos grupos de trabalhos realizados num dos encontros institucionais do PIBID, aprofundamos o estudo da temática em formação de professores, no conceito de interdisciplinaridade e apresentamos a análise advinda dos dados coletados junto aos relatórios dos GTs do IV Encontro do PIBID/UEL, ocorrido no ano de 2014, particularmente, as práticas desenvolvidas no subprojeto de Matemática. Analisando os documentos oficiais do PIBID (Brasil, 2007; Brasil, 2010; Brasil, 2013a; Brasil, 2013b) e destacando como a palavra interdisciplinaridade era contemplada, verificamos que apesar do presente termo ser mencionado inúmeras vezes nos documentos, não havia definição clara para o conceito de interdisciplinaridade. Diante desta constatação, buscamos a literatura para (re)construir, neste artigo, o conhecimento e as características de interdisciplinaridade e transdisciplinaridade.

Uma constatação interessante deu-se ao percebermos que, embasados no exemplo da Matemática, ao contrário do que se apregoa como necessidade para a interdisciplinaridade, ou seja, que vários agentes/docentes procurem integração para a realização de tarefas inter, multi ou transdisciplinares, a realidade complexa da ambiente escolar dificulta este entrosamento, o que não impede que as práticas interdisciplinares se realizem, uma vez que podem ser efetivadas por um único docente, desde que transite em outras áreas do conhecimento, como o 
que relatamos. Este exemplo do subprojeto de Matemática "Cultura Africana e Matemática" tornou clara as intenções pedagógicas desenvolvidas, voltadas para a interdisciplinaridade, bem como dos demais analisados nos relatórios, e revelou que a inserção dos estudantes IDs nas escolas modificou a realidade das mesmas e que as atividades integradoras estão presentes nos subprojetos PIBID/UEL, mesmo que nem sempre nomeadas adequadamente.

Concordando com os limites apresentados por Lélé \& Norgaard (2005) e as definições de Nicolescu (2010) para os termos multi, inter e transdisciplinar e, ainda, considerando a formatação do sistema escolar (aqui tomado como a fragmentação do tempo em disciplinas com docentes separados, consideramos que o que encontramos no PIBID/UEL aproxima-se da definição de transdisciplinaridade, pois os professores, a partir de seus conhecimentos tratam o tema "ao mesmo tempo entre as disciplinas, através das diferentes disciplinas e além de todas as disciplinas" (NICOLESCU, 2010, p.13). Neste contexto, lançamos a tese: estaríamos a caminho da transdisciplinaridade impulsionados pelo avanço no campo de conhecimento e limitados pelo formato da escola?

Ficou evidente que existe a necessidade de avançar o estudo quanto à forma de se construir e de se constituir a inter, a multi e a transdisciplinaridade, o que nos remete a refletir também, sobre as transformações nos cursos de formação de professores para que a prática interdisciplinar se configure no interior das ações pedagógicas.

\section{REFERÊNCIAS}

BRASIL. Ministério da Educação. Portaria Normativa n. 38 de 12 de dezembro de 2007. Dispõe sobre o Programa de Bolsa Institucional de Iniciação à Docência - PIBID. Diário Oficial da República Federativa do Brasil, Brasília, D.F., 13 de dezembro de 2007, p. 39.

BRASIL. Ministério da Educação. Coordenação de Aperfeiçoamento de Pessoal de Nível Superior - CAPES. Portaria no 260, de 30 de dezembro de 2010. Brasília, 2010. Disponível em https://www.capes.gov.br/images/stories/download/legislacao/Portaria260_PIBID2011_Noma sGerais.pdf Acesso em 20/03/2017.

BRASIL. Ministério da Educação. Coordenação de Aperfeiçoamento de Pessoal de Nível Superior - CAPES. Diretoria de Formação de Professores da Educação Básica. Relatório de Gestão PIBID 2009-2013. Brasília, 2013a. Disponível em https://www.capes.gov.br/images/stories/download/bolsas/2562014-relatrorio-DEB-2013web.pdf. Acesso em 20/03/2017. 
BRASIL. Ministério da Educação. Coordenação de Aperfeiçoamento de Pessoal de Nível Superior - CAPES. Portaria n⿳0 096, de 18 de julho de 2013. Brasília, 2013b. Disponível em https://www.capes.gov.br/images/stories/download/legislacao/Portaria_096_18jul13_Aprova RegulamentoPIBID.pdf Acesso em 20/03/2017.

CHARLOT, Bernard. Da relação com o saber. Porto Alegre: Artes Médicas Sul, 2000.

GATTI, Bernadete. et al. Um estudo avaliativo do Programa Institucional de Bolsa de Iniciação à Docência (PIBID). São Paulo: Fundação Carlos Chagas/SEP, 2014.

GERDES, Paulus. Ideias Matemáticas originárias da África e a educação Matemática no Brasil. Tópicos Educacionais, Recife, n.2, jun./dez. 2012.

HOUAISS, Antonio. Dicionário Houaiss da Língua Portuguesa. Rio de Janeiro: Objetiva, 2004.

LÉLÉ, Sharachchandra.; NORGAARD, Richard. B. Practicing interdisciplinarity.

BioScience. v. 55, n. 11, Nov. 2005, p. $967-975$.

NICOLESCU, Basarab. Para uma educação e aprendizagem transdisciplinaridades. In: O interdisciplinar - olhares contemporâneos. Ana Zahira Bassit (Org.). São Paulo: Factash, 2010, p. $11-24$.

ROGGERO, R. O Interdisciplinar na Universidade. In: O interdisciplinar - olhares contemporâneos. Ana Zahira Bassit (Org.). São Paulo: Factash, 2010, p. 139 - 152

SAVIANI, Dermeval. Formação de professores no Brasil: dilemas e perspectivas. Poíesís Pedagógica. v.9, n.1, jan./jun. 2011, p. 07 - 19.

SILVEIRA, M. R. A. A Dificuldade da Matemática no dizer do aluno: ressonâncias de sentido de um discurso. Educação e Realidade. Porto Alegre, v. 36, n. 3, p. 761-779, set./dez. 2011. Disponível em:

http://www.seer.ufrgs.br/index.php/educacaoerealidade/article/view/18480/14340. Acesso em $\underline{31 / 01 / 2017 .}$

\section{SOBRE AS AUTORAS}

\section{Ana Márcia Fernandes Tucci de Carvalho}

Doutora em Educação Matemática pela Universidade Estadual Paulista (UNESP). Professora da Universidade Estadual de Londrina (UEL), Docente do Programa de Pós-Graduação Mestrado Profissional em Matemática (PROMAT). Membro do Grupo de Pesquisa História na Educação Matemática. E-mail: anatuccicarvalho@gmail.com

\section{http://orcid.org/0000-0002-5480-0025}




\section{Andreia Maria Cavaminami Lugle}

Doutora em Educação Matemática pela Universidade Estadual Paulista (UNESP). Professora da Universidade Estadual de Londrina (UEL). Membro do Grupo de Pesquisa História e Ensino de História. E-mail: andreialugle@ uel.br

(iD) http://orcid.org/0000-0001-9582-1845

\section{Sandra Regina Ferreira de Oliveira}

Doutora em Educação pela Universidade Estadual de Campinas (UNICAMP). Professora da Universidade Estadual de Londrina (UEL). Docente do Programa de Pós-Graduação em Educação. Membro do Grupo de Pesquisa História e Ensino de História. E-mail: sandraoliveira.uel@gmail.com

iD http://orcid.org/0000-0002-9777- 4461 